\title{
MICROSPOROGÊNESE E ETAPAS DA ONTOGENIA DO GAMETÓFITO MASCULINO DE TABEBUIA OCHRACEA (CHAM.) STANDLEY (BIGNONIACEAE) ${ }^{1}$
}

Recebido em 10.01.95. Aceito em 10.08.95.

\author{
Nelson S. Bittencourt Jr. ${ }^{2}$
}

\begin{abstract}
RESUMO: (Microsporogênese e etapas da ontogenia do gametófito masculino de Tabebuia ochracea (Cham.) Standley (Bignoniaceae)). Foram analisadas as etapas da ontogenia do gametófito masculino e da parede da antera de Tabebuia ochracea. O método de formação da parede do microsporângio é do tipo Dicotiledôneo. O tecido esporogênico, em cada microsporângio, visto em secção transversal, organiza-se em uma fileira celular em forma de ferradura. O tapete é do tipo secretor e possui origem dual. $\mathrm{O}$ tapete interno diferencia-se precocemente em relação ao tapete externo. As duas camadas tapetais são estruturalmente dimórficas, mas no fim do estágio prémeiótico elas se tormam idênticas e com característico vacuoma bipolar. O endotécio desenvolve espessamentos helicoidais em suas paredes celulares. O desenvolvimento do pólen segue o modo usual em angiospermas. $\mathrm{O}$ expressivo crescimento do nucléolo e o aparecimento de vacúolos nucleolares na célula vegetativa sugerem sua alta atividade biossintetizante.
\end{abstract}

Palavras-chaves: Bignoniaceae, Tabebuia, ontogenia, tapete, placentóide, micrósporos, gametófito masculino, pólen, vacúolos nucleolares.

\begin{abstract}
Microsporogenesis and the early male gametophyte development of Tabebuia ochraceae (Cham.) Standley (Bignoniaceae)). Development of the pollen and anther wall of Tabebuia ochracea was studied. The microsporangial wall follows the Dicotyledoneous type of ontogeny. The sporogenous tissue in each microsporangium, in transverse section, is organized in a celular strip, with a horseshoe outline. The tapetum is secretory and shows a distinct dual origin. The inner tapetal layer differentiates earlier than the outher layer. The two tapetal layers exibit a distinct structural dimorphism, but before the meiotic divisions of the MMCs the tapetal layers become identical. Vacuolation in each tapetal cell, at this stage, is characteristically bipolar. The
\end{abstract}

\footnotetext{
'Trabalho realizado no Departamento de Botânica da Universidade Federal de Minas Gerais, Av. Antônio Carlos, 6627 - Cep. 31270-901 - Caixa Postal: 2486 - Pampulha - Belo Horizonte/MG - Brasil. Parte de uma monografia desenvolvida no período de agosto de 1988 a abril de 1992, sob orientação da Profa. Dra. M. M. Nogueira Braga e subsidiada com bolsa de Iniciação Científica do CNPq. Apresentado no XLV
Congresso Nacional de Botânica.

${ }^{2}$ Universidade do Vale do Rio dos Sinos - Departamento de Biologia - Centro de Ciências da Saúde, Av. Unisinos 950, Caixa Postal 275, CEP. 93.022-000 São Leopoldo - Rio Grande do Sul - Brasil.
} 
endothecium shows fibrous thickenings of the spiral type. The pollen grain development conforms with the usual way in angiosperms. The conspicuous growing of the nucleolus and nucleolar vacuolation into the generative cell sugests a high biosynthetic activity.

Key words: Bignoniaceae, Tabebuia, ontogeny, tapetum, placentoid, microspores, male gametophyte, pollen, nucleolar vacuoles.

\section{Introdução}

A literatura inicial sobre a embriologia da família Bignoniaceae foi revista por Schnarf (1931) e Davis (1966). A microsporogênese, o desenvolvimento do pólen e da parede do microsporângio, especificamente, foram investigados em Bignonia venusta (Duggar 1899), em Oroxylum indicum (Ghatak 1956), em Pyrostegia ignea ( $\sin$. P. venusta) e Tecoma stans, com ênfase sobre a ontogenia e a natureza do tapete (Gupta \& Nanda $1978 a, b$ e c), e em Tabebuia rosea, Millingtonia hortensis, Dolichandrone falcata, Heterophragma adenophyllum e Stereospermum cheloniodes (Mehra \& Kulkrani 1985). Informações fragmentárias foram ainda fornecidas por Raghavan \& Venkatasubban (1940) e Venkatasubban $(1944,1945)$ durante os estudos citológicos em Spatodea campanulata, Crescentia cujete, Dolichandrone reedii e Parmentiera serratifolia; por Gupta \& Nanda (1971), sobre o endotécio de Pyrostegia venusta a histoquímica da membrana tapetal de $P$. venusta e Tecoma stans (1972) e a estrutura do tapete de Bignonia, Jacaranda e Tecomaria (1978 c); e por Bhandari (1984) sobre o tapete de Pyrostegia e Tecoma. Johri (1992) organizou sistematicamente a literatura existente, embora tenha negligenciado alguns trabalhos de maior relevância para o grupo.

O presente trabalho procura caracterizar a ontogenia do gametófito masculino (até o estágio de pré-antese), do tapete e das camadas parietais do microsporângio de Tabebuia ochracea (Cham.) Standley (Bignoniaceae), árvore típica dos cerrados brasileiros e um dos ipês mais freqüentes no estado de Minas Gerais.

\section{Material e métodos}

O material utilizado no presente trabalho foi coletado de três árvores nativas (BHCB: 19821, 19857 e 19858) encontradas no Campus da Universidade Federal de Minas Gerais. Botões florais em diferentes estágios de desenvolvimento e flores foram fixados em FAA 50\% (Johansen 1940) por 24 horas e estocados em etanol $70 \%$. Receberam o tratamento usual em série etanol-xilol (Johansen 1940) para desidratação e inclusão em parafina. Cortes transversais e longitudinais seriados, de 4 a $20 \mu \mathrm{m}$, dependendo do estágio de desenvolvimento, foram feitos em micrótomo rotativo e corados com fucsina básica e azul-de-astra. Alguns testes histoquímicos usuais foram feitos em cortes à mão livre. Células do endotécio foram dissociadas em solução de Jeffrey (Johansen 1940) para exames dos espessamentos de paredes. 


\section{Resultados}

A flor de Tabebuia ochracea é zigomorfa, com 5-7 cm de comprimento. Sua corola é tubular-infundibiliforme, 5-lobada, com fauce achatada antero-posteriormente e exuberante coloração amarelo-ouro.

O androceu, incluso, é didínamo com estaminódio. Os quatro estames férteis, dois antero-laterais e dois postero-laterais, possuem anteras do mesmo tamanho e estruturalmente idênticas. O estaminódio, posterior, é muito reduzido e destituído de antera.

A antera é diteca e apicefixa. No botão floral a antera apresenta tecas contíguas que se separam amplamente na antese, como é usual em anteras divaricadas. A deiscência é longitudinal.

A antera é tetrasporangiada. Entretanto, próximo à antese o septo interesporangial se desintegra, formando, em cada teca, uma cavidade única dentro da qual se encontram os grãos polínicos, conferindo assim uma falsa impressão de antera biesporangiada.

Numa antera madura, em cada teca, o lóculo (loc) posiciona-se no lado ventral (Figura 1). Os tecidos que formam sua parede interna se encontram desorganizados e, na face voltada para o conectivo, distinguem-se duas massas conspícuas de células desorganizadas que correspondem aos restos do tecido placentóide (tp) de cada microsporângio. Flanqueando o lóculo de ambos os lados encontra-se um endotécio fibroso multiestratificado (en). O conectivo (co) é o tecido mais profundo e contém, em seu lado dorsal, um feixe vascular colateral (fv). Externamente a antera é revestida por epiderme uniestratificada (e).

Estômatos (es) são numerosos na porção proximal (ápice) da antera (Figura 2). Usualmente ocorrem apenas sobre o endotécio e/ou o conectivo - lado dorsal da antera. Abaixo da porção proximal da antera os estômatos são escassos ou totalmente ausentes. Pequenos tricomas glandulares capitados e subsésseis (tg) são também encontrados na mesma região onde os estômatos ocorrem (Figura 3).

O grão de pólen é simples, tricolpado (ocasionalmente tetracolpado e/ou sincolpado nos polos) e finamente reticulado (Figura $22 \mathrm{~g}$ e $h$ ).

Microsporogênese e desenvolvimento do gametófito masculino - A antera indiferenciada é constituída de uma massa homogênea de células meristemáticas, envolvidas por protoderme uniestratificada. A diferenciação se inicia bem cedo - quando o botão floral possui menos de um milímetro de comprimento. As células mais internas, que se diferenciam como tecido fundamental (conectivo - co) começam a se tornar vacuoladas e com núcleo excêntrico, salvo as células procambiais, no centro da antera (fpv - Figura 4). O arquespório hipodérmico (arq) se organiza nos quatro lobos da antera como um estrato de células ligeiramente altas, apresentando citoplasma denso e núcleo proeminente (Figuras 4 e 5). Células do conectivo, adjacentes ao lado interno do arquespório, apresentam um arranjo irregular idêntico ao das células subjacentes, mas permanecem não-vacuoladas e com conspícuo núcleo central (Figura 5 seta). 

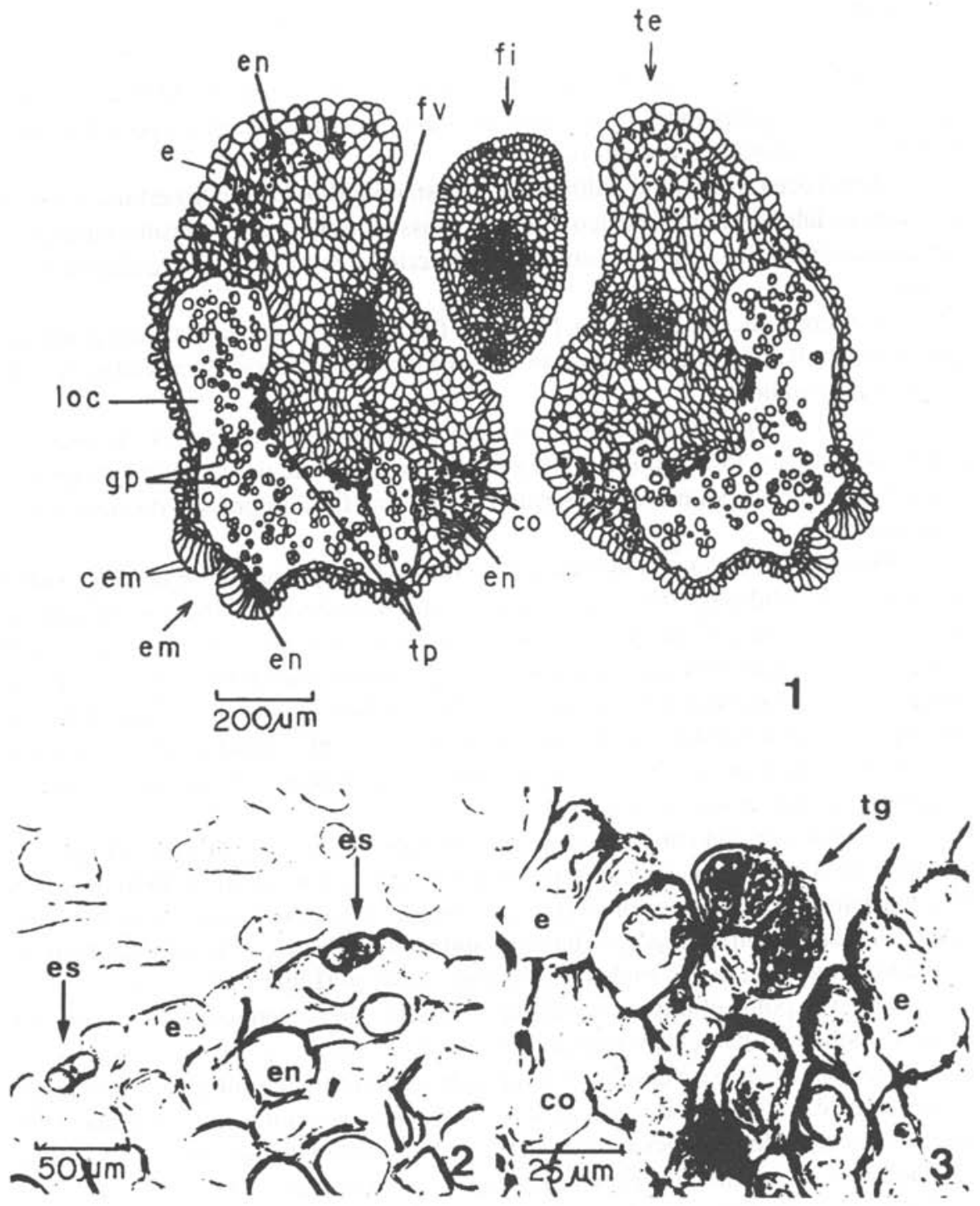

Fig. 1. Antera em estágio próximo à antese; secção transversal mediana. Fig. 2 e 3 . Teca, secção transversal apical. 2. Epiderme com estômatos. 3. Epiderme com tricoma glandular: cem=células estomiais, $\mathrm{co}=$ conectivo, $\mathrm{e}=$ epiderme, em=estômio, en=endotécio, es=estomato, fi=filete, $\mathrm{fv}=$ feixe vascular, $\mathrm{gp}=\mathrm{grãos}$ de pólen, loc=lóculo, te=teca, tg=tricoma glandular, tp=tecido placentóide (desorganizado). 
Subseqüentemente, as células do arquespório sofrem divisões periclinais, dando origem à camada parietal primária (cpp), adjacente à epiderme, e à camada esporogênica (ce) no lado interno (Figura 6). As células esporogênicas destacam-se das demais por sua coloração mais intensa e núcleos mais conspícuos. Visto em secção transversal, o tecido esporogênico de cada microsporângio geralmente se organiza em uma fileira, em forma de ferradura, contendo cerca de 8-12 células. As células esporogênicas multiplicam-se copiosamente por divisões anticlinais, antes de se diferenciarem em microsporócitos ou células-mãe dos micrósporos (CMMis).

A medida em que a antera se desenvolve, a concavidade dos microsporângios se acentua. Após a divisão do arquespório, as células da camada parietal primária rapidamente sofrem novas divisões periclinais, formando a camada parietal secundária externa ( $\left.\mathrm{cps}_{1}\right)$, voltada para a epiderme, e a camada parietal sacundária interna $\left(\mathrm{cps}_{2}\right)$, adjacente ao lado epidérmico do tecido esporogênico (Figura 7). No lado interno deste último, o conectivo, cujo desenvolvimento prossegue acompanhando o do esporângio, caracteriza-se por um tecido parenquimatoso de células vacuoladas, salvo nos dois ou três estratos mais periféricos, cujas células apresentam denso citoplasma e núcleo proeminente. Gradualmente as células do conectivo que ficam em contato direto com o tecido esporogênico - iniciais do tapete interno (iti) - começam a se expandir, formando assim a camada tapetal interna (tin).

A camada parietal secundária externa divide-se periclinalmente, dando origem ao endotécio hipodérmico (en), voltado para a epiderme, e à camada média $(\mathrm{cm})$, no lado interno (Figura 8). Em uma das extremidades do microsporângio, entretanto, onde futuramente desenvolver-se-á o endotécio fibroso multiestratificado, três ou quatro estratos celulares são encontrados. Já a camada parietal secundária interna passa diretamente a funcionar como camada tapetal externa (tex).

Nesse estágio cada microsporângio (em secção transversal) possui uma fileira de aproximadamente 30-50 células esporogênicas - bastante distintas devido aos seus densos citoplasmas e núcleos muito proeminentes. Daí por diante o número de células esporogênicas se mantém, havendo ainda o crescimento por expansão celular. $\mathrm{O}$ tapete, em ambos os lados da camada esporogênica, também se apresenta com células de denso citoplasma e núcleo proeminente, porém não tanto quanto as desta última. Não obstante, o tapete interno (tin) distingue-se histologicamente do tapete externo (tex), pois o primeiro apresenta células com citoplasma menos denso, binucleadas e um pouco mais amplas (Figura 8). Sob o tapete interno, o conectivo torna-se tal como uma proeminência introduzindo-se na concavidade do microsporângio tecido placentóide (tp) - , sendo que as células adjacentes ao tapete interno são pequenas e apresentam denso citoplasma, contrastando com as células mais amplas e
vacuoladas da região mais interna.

Posteriormente, as células do tapete interno crescem e começam a tornar-se vacuoladas (Figura 9). Os vacúolos surgem quase sempre no polo voltado para o tecido esporogênico. Algumas das células do tapete interno passam a ser tetranucleadas. As células do conectivo adjacentes ao tapete interno também tornam-se vacuoladas. Uma fileira de 8-16 células, as células epidérmicas de cada lado do sítio de ruptura 


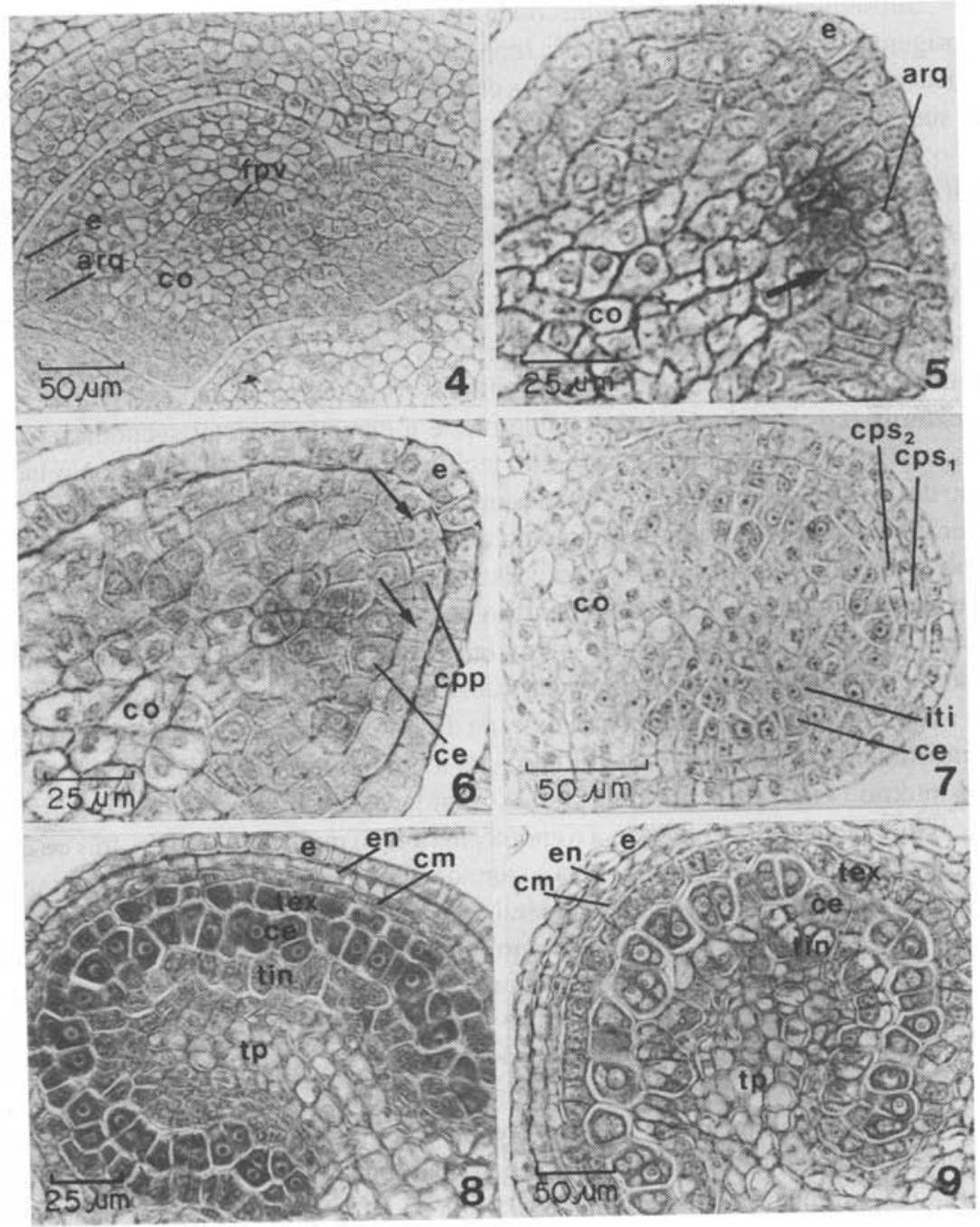

Fig. 4-9. Secções transversais de anteras em desenvolvimento. 4. Antera com arquespório hipodérmico (arq). 5. Teca com arquespório (arq). Setas: ver explicações no texto. 6. Microsporângio com camada esporogênica (ce) e camada parietal primária (cpp). A última, em alguns locais (setas), já sofreu divisão periclinal. 7. O mesmo com camada esporogênica (ce) em formato de ferradura, camadas parietais secundárias externa $\left(\mathrm{cps}_{1}\right)$ e interna $\left(\mathrm{cps}_{2}\right)$ e iniciais do tapete interno (iti). 8. Microsporângio após a divisão da camada parietal secundária externa, que deu origem ao futuro endotécio (en) e à camada média $(\mathrm{cm}) .9$. $\mathrm{O}$ mesmo com células do tapete interno (tin) mais amplas e vacuoladas que as do tapete externo (tex). arq $=$ arquespório, $\mathrm{ce}=$ camada esporogênica, $\mathrm{cm}=$ camada média, $\mathrm{co}=$ conectivo, $\mathrm{cpp}=$ camada parietal primária, $\mathrm{cps}_{1}$ e $\mathrm{cps}=$ =camadas parietais secundárias externa e interna, respectivamente, $\mathrm{e}=\mathrm{epiderme}$, en=endotécio, fpv=feixe pró-vascular, iti=iniciais do tapete interno, tex=tapete externo, tin=tapete interno, tp=tecido placentóide. 

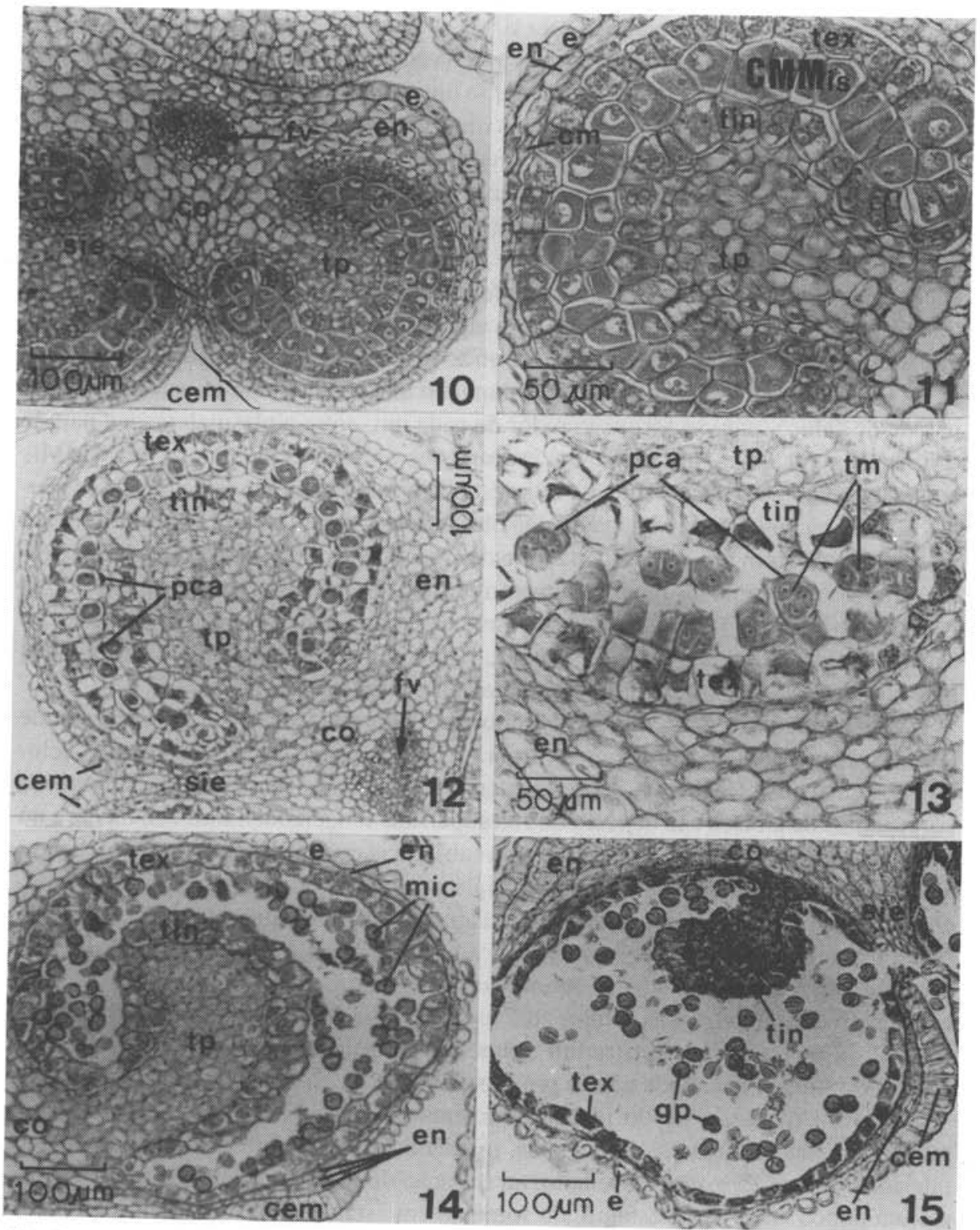

Fig. 10-15. Seç̧ões transversais de anteras em desenvolvimento. 10. Teca com CMMis próximas à maturidade. 11. Um dos microsporângios da figura anterior em maior aumento. 12. Microsporângio pouco antes da primeira divisão meiótica. 13. Extremidade de um microsporângio contendo tétrades tetraédricas de micrósporos (tm), envolvidas por parede de calose (pca). 14. Microsporângio com micrósporos livres uninucleados (mic). 15. Microsporângio após retração do tecido placentóide (tp) e colapso das cámadas parietais (seta). cem=células estomiais, $\mathrm{cm}=$ camada média, CMMis=células mães dos micrósporos, $\mathrm{co}=$ conectivo, e=epiderme, en=endotécio, fv=feixe vascular $\mathrm{gp}=\mathrm{grãos}$ de pólen, mic=micrósporos, $\mathrm{pca}=$ parede de calose, sie=septo interesporangial, tex=tapete externo, tin=tapete interno, tm=tétrades de . micrósporos, $\mathrm{t} p=$ tecido placentóide, 
do estômio - células estomiais (Figura 10) — começam a se alongar anticlinalmente e, abaixo delas, as células do endotécio ou as da camada média sofrem divisões periclinais resultando em dois ou três estratos. Na outra extremidade do microsporângio o endotécio continua a se desenvolver, sendo que suas células tornam-se mais amplas e vacuoladas, praticamente iguais as do conectivo.

Em seguida as células do tapete externo também aumentam em volume, passam a apresentar-se bi ou tetranucleadas e iniciam vacuolação (Figura 11); contudo permanecem ainda distintas das células do tapete interno, pois as últimas são maiores e mais vacuoladas. O incremento do formato em ferradura da camada de CMMis (em secção transversal) alcança seu grau máximo. Em algumas regiões, especialmente nas extremidades, a camada de CMMis pode encontrar-se biestratificada (Figuras 10 e 11).

Os microsporócitos atingem o seu tamanho máximo, tornam-se esféricos e uma parede de calose (pac) se forma ao redor de cada um, entre a plasmalema e a parede celular (Figura 12) - nas presentes preparações as paredes de calose das CMMis adquiriram uma coloração violeta. Nesse estágio a camada média se desintegra e apenas os seus remanecentes esmagados são observados. Antes das CMMis entrarem em meiose o tapete atinge o seu grau máximo de crescimento (Figura 12). O tapete externo torna-se praticamente igual ao tapete interno e ambos apresentam agora ampla vacuolação bipolar. Grãos de amido se desenvolvem em todo o conectivo e endotécio, especialmente na região entre os dois microsporângios de cada teca e nos tecidos placentóides. As células epidérmicas começam a tornar-se papilosas.

Os meiócitos sofrem meiose e a citocinese simultânea resulta na formação de tétrades tetraédricas de micrósporos (Figura 13). Ocorre dissolução das paredes celulares originais das CMMis e, subseqüentemente, das paredes de calose. Numerosos corpúsculos de Ubisch são depositados na superfície tangencial interna do tapete e no citoplasma de suas células observa-se uma substância que, nas presentes preparações, adquiriu uma coloração parda. Nesse estágio os micrósporos já se encontram isolados, expandiram-se consideravelmente e já apresentam a estrutura típica da parede do pólen maduro (Figuras 14 e 22 a). O seu núcleo é bastante proeminente. Tal como ocorreu com a camada média, o endotécio se degenera, salvo nos flancos da teca e ocasionalmente em algumas células abaixo das células estomiais (Figuras 14 e 15). O estômio já apresenta a sua estrutura típica, exceto pelo espessamento cuticular das células estomiais, que ainda não se processou.

Normalmente, o tecido placentóide, então, se desorganiza, tornando-se uma massa compacta de células esmagadas, mantendo ainda os grãos de amido em seu interior (Figuras 15 e 16). Entretanto, tal retração do tecido placentóide pode ter início um pouco antes deste estágio, ou somente em estágio mais avançado (comparar com a Figura 19). As camadas tapetais começam a se degenerar. O tapete interno volta a se apresentar morfologicamente distinto do tapete externo, mas desta vez simplesmente devido ao encolhimento do tecido placentóide, fazendo com que as células do tapete interno se tornem comprimidas umas contra as outras, conseqüentemente aparentando serem mais altas do que as do tapete externo (Figuras 14-15). Estas últimas, por sua vez, tendem a se tornar achatadas e seus protoplasmas começam a se 
retrair, dando a impressão de que as células se separam umas das outras, embora suas paredes celulares permaneçam intactas (Figura 15). Finalmente os restos protoplasmáticos de ambos os tapetes tornam-se esferoidais (Figuras 17 e 18), deixando apenas a membrana tapetal (mt) incrustrada de corpúsculos de Ubisch (Figura 18) e as paredes anticlinais.

Ainda nesse estágio numerosos vacúolos esferoidais se desenvolvem no protoplasma dos micrósporos, dando início à diferenciação do gametófito masculino (Figura $22 b$ ). Ao mesmo tempo o núcleo do pólen é deslocado para junto da parede e sofre mitose, originando a célula generativa $(\mathrm{cg})$ e a célula vegetativa. $\mathrm{O}$ núcleo da célula vegetativa (ncv) volta a ocupar mais ou menos a posição central. A célula generativa, por seu turno, menor e de formato lenticular, permanece adjacente à parede do grão de pólen, entre um colpo e outro (Figura $22 c$ ).

O espessamento cuticular se processa nas células estomiais e nas células epidérmicas adjacentes ao endotécio multiestratificado. Nos lados da teca as células do endotécio começam a diferenciar os espessamentos helicoidais lignificados em suas paredes, inicialmente no estrato subepidérmico, continuando nos estratos mais profundos (Figuras 20 e 21). Ocasionalmente tais espessamentos se desenvolvem também nas células remanecentes abaixo das células estomiais, mas neste caso os espessamentos são muito tênues. A membrana tapetal adere-se junto aos restos de tecidos degenerados da parede do microsporângio (Figura 19).

Gradualmente os vacúolos do grão de pólen desaparecem. A célula generativa é englobada pelo protoplasma da célula vegetativa (Figura $22 d$ e $e$ ). Nesse estágio, diminutos vacúolos podem ser observados no citoplasma da célula generativa. No núcleo da célula vegetativa o nucléolo expande-se, consideravelmente, e passa a apresentar internamente uma ou mais regiões claras, de formato esferoidal (Figura $22 d$ f). Tais regiões, freqüentemente, se tornam bastante conspícuas. Numerosos grãos de amido se desenvolvem no protoplasma da célula vegetativa, ao mesmo tempo em que a célula generativa se torna fusiforme. De um modo geral esta última se posiciona lateralmente adjacente ao núcleo da célula vegetativa (Figura $22 f$ ).

\section{Discussão}

A freqüência de estômatos nas anteras está relacionada com o processo de deiscência. Segundo Schmid (1976), a deiscência é essencialmente um processo dessecativo e os estômatos presentes na antera podem ser funcionais - abrir e fechar periodicamente - ou semifuncionais - permanentemente abertos —, podendo assim acelerar a perda de água.

Tricomas glandulares semelhantes aos encontrados nas anteras de Tabebuia ochracea já foram observados também no lado dorsal da antera de Pyrostegia ignea (Gupta \& Nanda 1978 a) e de Distictella sp. (Barroso 1986).

O desenvolvimento da parede da antera é do tipo Dicotiledôneo (Davis 1966). $\mathrm{O}$ tapete possui origem dual, derivando-se parcialmente das camadas parietais e parcialmente das células do conectivo, confirmando assim os estudos de Periasamy \& 


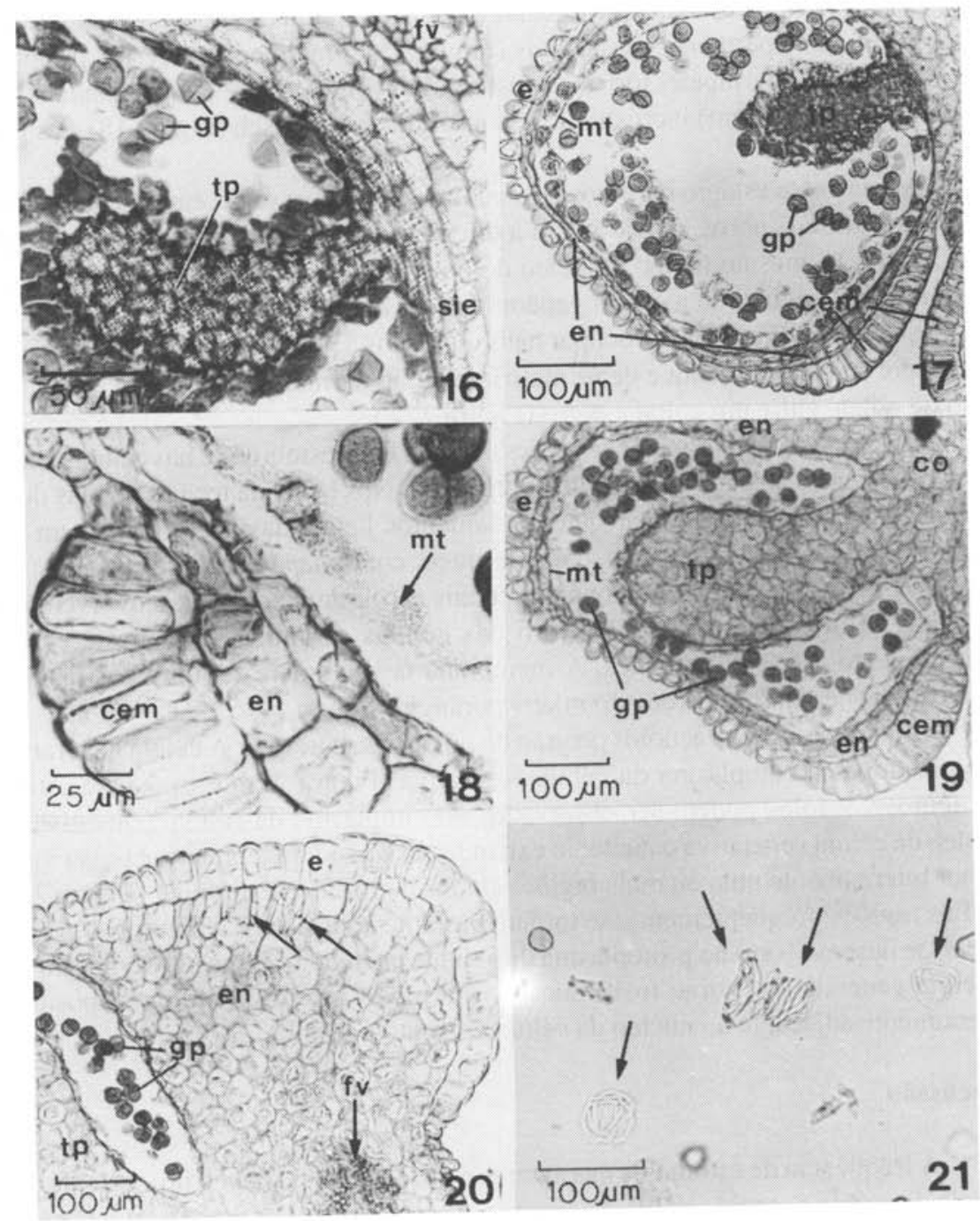

Fig. 16-20. Secções transversais de anteras em desenvolvimento. 16. Tecido placentóide (tp) (degenerado) e septo interesporangial (sie) com corpúsculos brilhantes, correspondendo a grãos de amido em luz polarizada. 17. Microsporângio apresentando tapete com protoplastos esferoidais (degenerados). Estômio desenvolvido. 18. Detalhe da parede da antera mostrando membrana tapetal $(\mathrm{mt})$ incrustrada de corpúsculos de Ubisch. 19. Microsporângio com tapete totalmente degenerado e membrana tapetal $(\mathrm{mt})$ aderindo-se aos restos esmagados dos tecidos parietais. Tecido placentóide ainda intacto. 20. Endotécio diferenciando espessamentos helicoidais nas paredes celulares (setas). Fig. 21. células do endotécio dissociadas com espessamentos helicoidais de paredes. cem=células estomiais, $\mathrm{co}=$ conectivo, e=epiderme, en=endotécio, $\mathrm{fv}=$ feixe vascular, $\mathrm{gp}=\mathrm{grãos}$ de pólen, $\mathrm{mt}=$ membrana tapetal, sie=septo interesporangial, $\mathrm{t}=$ =tecido placentóide. 


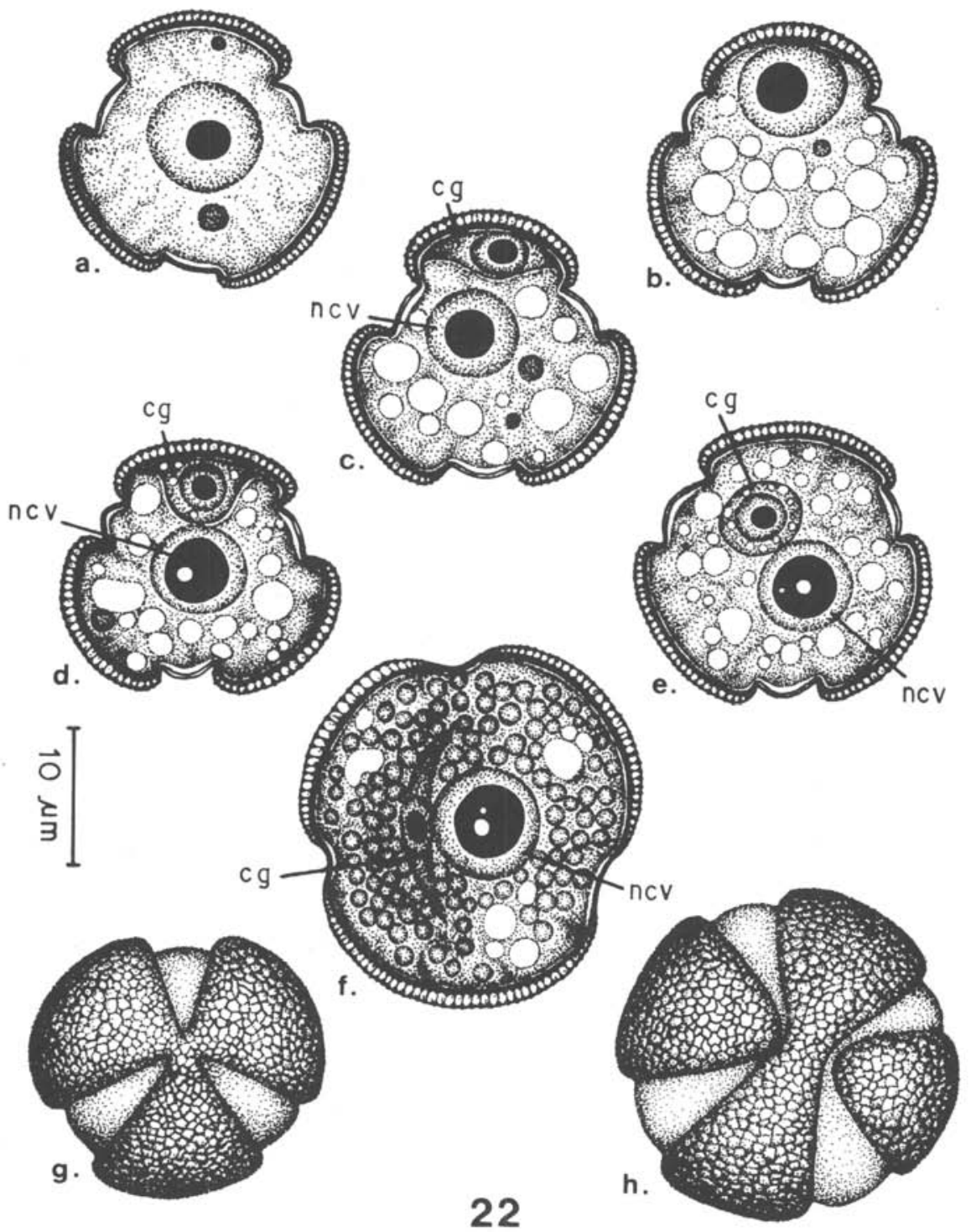

Fig. 22. a-f: Secçōes transversais de micrósporos e gametófitos masculinos em sucessivos estágios de desenvolvimento. $a$ : micrósporo. $b$ : estágio pré-mitótico. Vacuolação do protoplasma. $c$ : após a mitose. $d$ e $e$ : Célula generativa é englobada pelo protoplasma da célula vegetativa. Expansão do nucléolo e formação de vacúolos nucleolares no núcleo da célula vegetativa. $f$ : O protoplasma da célula vegetativa se torna rico em grãos de amido. A célula generativa se torna fusiforme. $g$ : Aspecto externo de um grão de pólen tricolpado. $h$ : Aspecto externo de um grão de pólen tetracolpado e sincolpado. Todos em vista polar. $\mathrm{cg}=$ célula generativa, $\mathrm{ncv}=$ núcleo da célula vegetativa, ga=grãos de amido. 
Swamy (1966) sobre a origem e a natureza do tapete em angiospermas.

Segundo Periasamy \& Swamy (1964), freqüentemente a porção interna do tapete mostra, durante os primeiros estágios de diferenciação, um arranjo irregular de suas células, em contraste com o arranjo bastante regular da porção externa do tapete. Em Tabebuia ochracea, células do conectivo adjacentes ao lado interno do tecido esporogênico, apresentando denso citoplasma e núcleo proeminente, diferenciam-se numa camada tapetal concomitantemente ou logo após a divisão periclinal da camada parietal primária; portanto o início de diferenciação do tapete interno é anterior ao do tapete externo, uma vez que a camada parietal secundária interna diferencia-se diretamente em tapete externo. Em Heterophragma adenophylum o tapete interno também é o primeiro a se diferenciar (Mehra \& Kulkrani 1985). Segundo os mesmos autores, em Tabebuia rosea, não obstante, o contrário é observado, ou seja, o tapete externo se diferencia antes do tapete interno, e, no restante das espécies por eles estudadas, ambos os tapetes diferenciam-se simultaneamente. Em Pyrostegia ignea e Tecoma stans, tal como em Tabebuia ochracea, o tapete interno começa a se diferenciar antes do tapete externo (Gupta \& Nanda $1978 a, b$ e $c$ ).

Morfologicamente, a diferença de estágio de desenvolvimento entre os tapetes interno e externo de Tabebuia ochracea persiste até a maturidade das CMMis, quando, por fim, os dois tapetes tornam-se idênticos. Aparentemente por esta razão, na maior parte do seu período de desenvolvimento os tapetes interno e externo apresentam significante dimorfismo.

Embora a origem dual e a natureza dimórfica do tapete tenham sido observadas em todas as Bignoniaceae estudadas por Gupta \& Nanda (1978 $a, b$ e $c$ ) e Mehra \& Kulkrani (1985), tais autores não fazem menção alguma sobre o fato de os tapetes interno e externo se igualarem no final da fase pré-meiótica, o que foi caracteristicamente observado em Tabebuia ochracea.

O tapete permanece intacto até a formação dos micrósporos uninucleados portanto é do tipo secretor e não do tipo amebóide, como sugerido por Davis (1966) - e desenvolve uma distinta membrana incrustrada de corpúsculos de Ubisch membrana tapetal (Gupta \& Nanda 1972).

A vacuolação bipolar das células do tapete próximo ao estágio de divisão meiótica foi também observada em Tabebuia rosea (Mehra \& Kulkrani 1985). Não obstante, segundo os mesmos autores, ao amadurecer o endotécio de $T$. rosea não desenvolve os espessamentos em suas paredes celulares; já em $T$. ochracea observase a formação de um expressivo endotécio fibroso multiestratificado, embora restrito a quatro sítios em cada antera. Endotécio com este mesmo comportamento foi observado em Pyrostegia ignea e Tecoma stans (Gupta \& Nanda 1978 a e b). Ghatak (1956) descreveu o desenvolvimento de um endotécio fibroso multiestratificado em Oroxylum indicum, mas não forneceu nenhuma ilustração que consubstanciasse sua exposição.

Segundo Schmid (1976, p. 304), "Although it is generally acknowledged that the actual force resulting in dehiscence of anthers is in some manner related to the endothecium (when present), the exact physical mechanism for dehiscence still has 
not been adequately clarified." A natureza espiralada dos espessamentos de parede das células do endotécio de Tabebuia ochracea - também observada em Pyrostegia ignea e Tecoma stans (Gupta \& Nanda 1978 b e $c$ ) - descarta a possibilidade do endotécio de tais espécies atuar na deiscência da antera por um processo de coesãoadesão exatamente igual ao usualmente admitido (ver descrição fornecida por Fahn 1990, p. 431). Especula-se se o endotécio de Tabebuia ochracea não estaria também envolvido, por um processo higroscópico, no movimento das tecas, responsável pelo seu posicionamento após a antese. Estudos mais aprofundados da topografia do endotécio e de sua natureza quanto aos espessamentos de parede, com relação a sua função na antera como um todo, tornam-se, portanto, necessários.

Nos micrósporos da espécie presentemente estudada, a seqüência de eventos até a maturidade do gametófito masculino segue o padrão usual em angiospermas, segundo Maheshwari (1949). Gentry (1973) e Silvestre \& Melhem (1989) citam o pólen de Tabebuia ochracea como tricolpado apenas, mas no presente trabalho foram ocasionalmente observados também grãos polínicos tetracolpados.

Durante o desenvolvimento do gametófito masculino observou-se um crescimento significativo do nucléolo na célula vegetativa e o aparecimento, em seu interior, de áreas claras arredondadas. O nucléolo é o local de síntese e processamento de rRNA, bem como da reunião de proteinas em partículas pré-ribossômicas (Goessens 1984). Segundo o mesmo autor, o número de nucléolos, seu tamanho e sua forma variam amplamente dependendo do organismo, do tipo de célula, da sua ploidia, ou do seu estado fisiológico, sendo que o aumento do tamanho do nucléolo de uma célula freqüentemente está relacionado com o incremento de sua atividade sintetizante.

As áreas esferoidais claras, observadas no nucléolo da célula vegetativa, são conhecidas na literatura como vacúolos ou interstícios nueleolares (Moreno-Dias de la Espina et al. 1980; Goessens 1984). Admite-se também que estejam relacionados com uma elevada atividade biossintética das células que os possuem, desempenhando um papel no transporte e reserva de precursores pré-ribossômicos (Moreno-Dias de la Espina et al. 1980). Portanto, o pronunciado crescimento do nucléolo, bem como o surgimento de vacúolos nucleolares, sugerem uma alta atividade sintetizante da célula vegetativa, durante a maturação do gametófito masculino. Tal atividade certamente relaciona-se também com a expressiva formação de grãos de amido no protoplasma da célula vegerativa neste período.

O encolhimento do tecido placentóide pode ser observado em estágios diferentes, mas sempre no final da maturação da antera. As vezes uma mesma antera pode apresentar um ou mais tecidos placentóides desorganizados e outros ainda intactos. Tais observações sugerem ser a retração do tecido placentóide uma conseqüência da dessecação implicada no processo de deiscência da antera. Da mesma forma, a desorganização e a ruptura do septo interesporangial pode ocorrer em estágios diferentes, mas sempre no final do desenvolvimento da antera.

Na maturidade as células epidérmicas adjacentes à linha de deiscência - células estomiais (expressão utilizada por Woycicki (1924), referindo-se à mesma estrutu- 
ra em outras espécies) - tornam-se radialmente alongadas e com cutícula espessa, o que representa, nas palavras de Mehra \& Kulkrani (1985, p. 249) "uma peculiaridade obviamente associada ao mecanismo de deiscência da antera".

\section{Agradecimentos}

Ao Depto. de Botânica - ICB - UFMG e à Prof. Dra. Marilene M. Nogueira Braga, pela oportunidade de realização deste trabalho. Ao CNPq, pela bolsa de Iniciação Científica. Ao Lab. de Anatomia Vegetal do Depto. de Botânica - UFRGS, na pessoa do Prof. Dr. Jorge E. A. Mariath, pelos auxílios na montagem final deste artigo.

\section{Referências bibliográficas}

Barroso, G. M. 1986. Sistemática de Angiospermas do Brasil. Vol. 3. Viçosa: UFV, Impr. Univ.

Bhandari, N. N. 1984. The microsporangium. In: Johri, B. M. (ed.). Embryology of Angiosperms. Berlin: Springer-Verlag. p. 53-121.

Davis, G. L. 1966. Systematic Embryology of the Angiosperms. New York: John Wiley \& Sons.

Duggar, B. M. 1899. On the development of the pollen grain and the embryosac in Bignonia venusta. Bull. Torrey bot. Club 26: 89-105.

Fahn, A. 1990. Plant Anatomy: Oxford: Pergamon Press.

Gentry, A. H. 1973. Bignoniaceae. In: Flora of Panama. Ann. Mo. bot. Gdn. 60: 781-997.

Ghatak, J. 1956. A contribution to the life history of Oroxylum indicum Vent. Proc. Indian Acad. Sci. B 43: 73-83.

Goessens, G. 1984. Nucleolar structure. Int. Rev. Cytol. 87: 107-158.

Gupta, S. C. \& Nanda, K. 1971. Endothecium in Pyrostegia venusta. Curr. Sci. 40: 470-471.

Gupta, S. C. \& Nanda, K. 1972. Occurrence and histochemistry of the anther tapetal membrane. Grana 12: $99-104$.

Gupta, S. C. \& Nanda, K. 1978a. Ontogeny and histochemistry of dimorphic tapetum in Tecoma stans anthers. Bull. Soc. Bot. France 125: 129-134.

Gupta, S. C. \& Nanda, K. 1978b. Studies in the Bignoniaceae. I. Ontogeny of dimorphic anther tapetum in Pyrostegia. Am. J. Bot. 65(4): 365-399.

Gupta, S. C. \& Nanda, K. 1978c. Studies in the Bignoniaceae. II. Ontogeny of dimorphic anther tapetum in Tecoma. Am. J. Bot. 65(4): 400-405.

Johansen, D. A. 1940. Plant Microtechnique. New York: McGraw-Hill.

Johri, B. M.; Ambegaokar, K. B. \& Srivastava, P. S. 1992. Comparative Embryology of Angiosperms. Vol. 2. Berlin: SpringerVerlag.

Maheshwari, P. 1949. The male gametophyte of angiosperms. Bot. Rev. 15: 1-75.

Mehra, K. R. \& Kulkarni, A. R. 1985. Embryological studies in Bignoniaceae. Phytomorphology 35(3,4): 239-251.

Moreno-Dias de la Espina, S.; Medina, F. J. \& Risueño, M. C. 1980. Correlation of nucleolar activity and nucleolar vacuolization in plant cells. Eur. J. Cell Biol. 22: 724-729.

Periasamy, K. \& Swamy, B. G. L. 1964. Is the microsporangium of angiosperms wall-less? Curr. Sci. 34(2,3): 735-738.

Periasamy, K. \& Swamy, B. G. L. 1966. Morphology of the anther tapetum of angiosperms. Curr. Sci. 35(17): 427-430.

Raghavan, T. S. \& Venkatasubban, K. R. 1940. Studies in the Bignoniaceae. I. Chromosome number and epidermal hydathodes in Spathodea campanulata. J. Indian bot. Soc. 19: 293-298.

Schmid, R. A. 1976. Filament histology and anther dehiscence. Bot. J. Linn. Soc. 73: 303-315.

Schnarf, K. 1931. Vergleichende Embyologie der Angiospermen. Berlin: Gebrüder Borntraeger. 
Silvestre, M. S. F. \& Melhem. T. S. A. 1989. Flora polínica da reserva do Parque Estadual das Fontes do Ipiranga (São Paulo, Brasil). Hoehnea 16: 211-228.

Venkatasubban, K. R. 1944. Cytological Studies in Bignoniaceae. Annamalai Univ. Publ. 1, 2 \& 3: 1-207 apud Mehra, K. R. \& Kulkarni, A. R. 1985. Embryological studies in Bignoniaceae. Phytomorphology $35(3,4): 239-251$.

Venkatasubban, K. R. 1945. Cytological Studies in Bignoniaceae. IV. The cytology of Dolichandrone reedii Seem. and allied genera. Proc. Indian Acad. Sci. B 21: 77-92.

Woycicki, Z. 1924. Recherches sur la déhiscence des anthèrs et el rôle du stomium. Revue gén. Bot. 36: 196-212, 256-258. 